\title{
Analysis of modifications to reduce the cost of obtaining an electric cable in the auto industry
}

\author{
Ancuța BĂLTEANU, Monica BÂLDEA \\ University of Pitesti, Pitesti, Romania \\ ${ }^{*}$ Corresponding author e-mail: ancuta.balteanu@upit.ro \\ Article history \\ Received 18.06.2019 \\ Accepted 15.08.2019 \\ DOI https://doi.org/10.26825/bup.ar.2019.004
}

\begin{abstract}
In this paper are presented some proposals to modify the electric wiring used in the automotive industry, in order to reduce the cost of obtaining this product. The modifications mainly concern the materials used to obtain the electrical wiring. Of course, these changes are the fruit of the analysis of the process of carrying out the studied wiring. Once they have been identified and presented, all these proposed changes will subsequently go through an analysis of the associated risks, for each of them separately. Subsequently, the validation of the proposals will be carried out. Finally, based on the results of the validation analyzes, the management of the organization will make the necessary decisions regarding the possibility or impossibility of implementing these changes on the studied electrical wiring.
\end{abstract}

Keywords: electrical wiring, trim, electric relay, welding, traction, reliability, costs.

\section{Introduction}

A wiring harness is a set of wires that connects the various components used for the electrical and electronic functions of a car [1]. It ensures the supply of electricity, data and control impulse control between the different electrical and electronic equipment, to ensure all the electrical connections of the car.

The main materials used in the production of wiring are: wires, connectors, tape of different types, mechanical and thermal protection [2].

Following the analysis of the process of carrying out the studied wiring, there were identified some modifications that can be made effectively to reduce the cost of the materials used.

These changes are as follows:

- changing the type of shading,

- moving a relay to the relay and fuse box,

- area modification of wires that have no electrical role.

After establishing the proposed modifications, the risks will be realized and analyzed for each of the 3 proposed changes. Based on the results obtained, decisions will be made regarding the possibility of implementing these modifications on the wiring [3].

In order to validate a modification of any type, a feasibility meeting is held together with the other departments involved, namely those of quality, cutting, assembly, etc. 


\section{Modification the type of splice}

Through splice the aim is to isolate the wires in order to protect them. Splicing it is made with tape of different types, splicing it can be made over GAF tubes or directly on the wires.

Thus, in this case 2 types of can be used splice: splice dense - with cover - Figure 1.a, splice rare without cover - Figure 1.b.
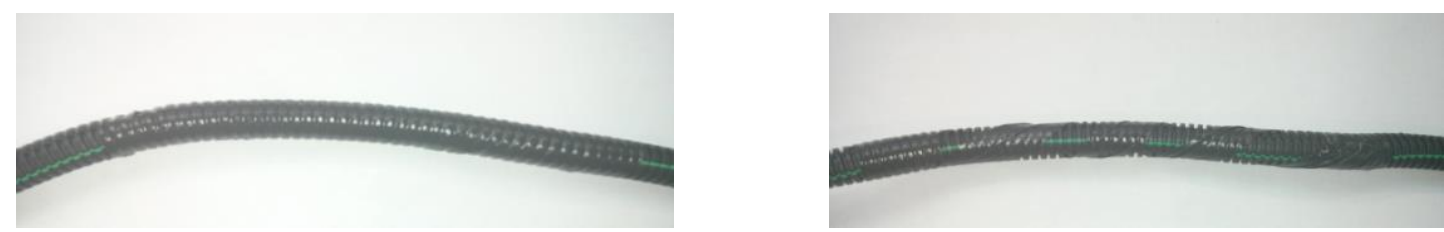

Figure 1 Splice over the GAF tube

a. with cover

b. without cover

\section{Moving a relay in the relay and fuses box}

Another change that will lead to a reduction in the cost of the materials used is the use of an existing space in the box where the relays and fuses are mounted, a space where no relay is mounted on any reference. Figure 2.a shows the relays and fuses box before the modification.

Due to the identification of this vacant space, another relay can be moved, which would have been mounted in this box as well. This relay will be mounted on a connector that is inserted into the relay box. Figure 2.b shows the relays and fuses box after the modification. As a result of this change, the connector on which the relay is mounted is removed and thus four wires shorten its length by $50 \mathrm{~mm}$.
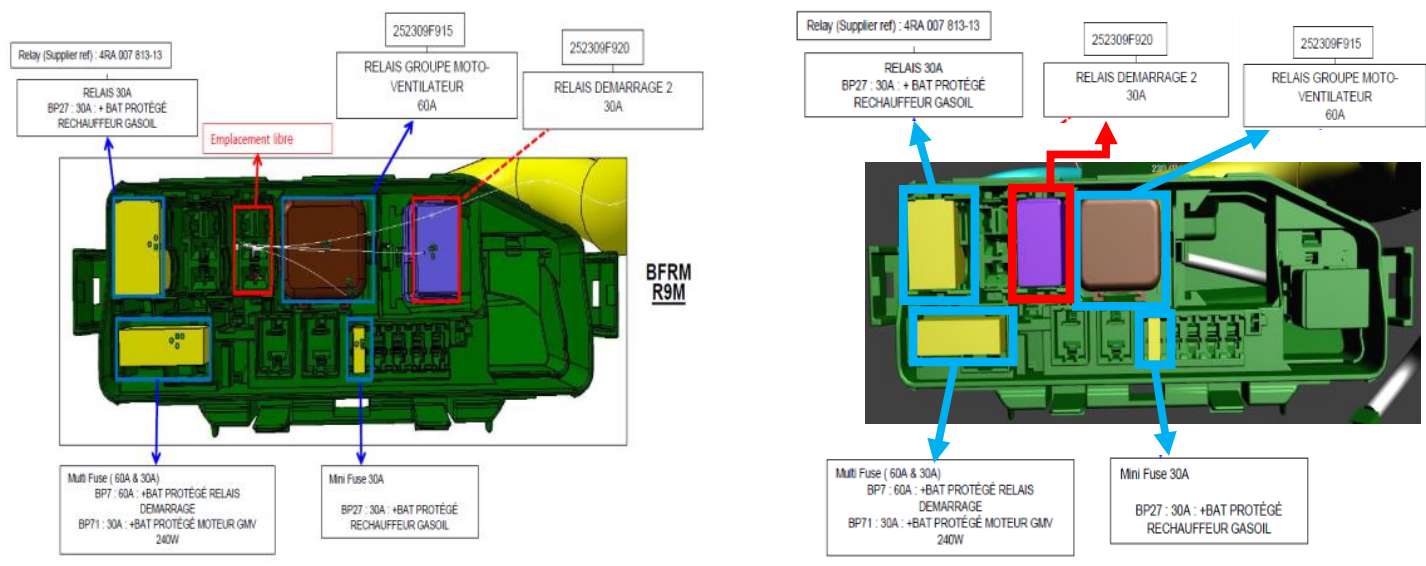

Figure 2 Relays and fuses box

a. before the change

b. after the change

\section{Elimination of any fire which do not have an electrical rol}

In the table welds MH-12A and MH-12B were detected four wires that have no electrical role. These electrical wires they are called dead electrical wires and have the role of balancing the welds.

Figure 3.a shows the current welding sheet for welding MH-12A, without removing the dead wire 25386. Initially, this weld had a total cross-section of $10.5 \mathrm{~mm}$, and after removing the wire 25386 this weld will have the cross-section of $9.75 \mathrm{~mm}$. Figure 3.b shows the welding sheet after modification for MH-12A welding. 

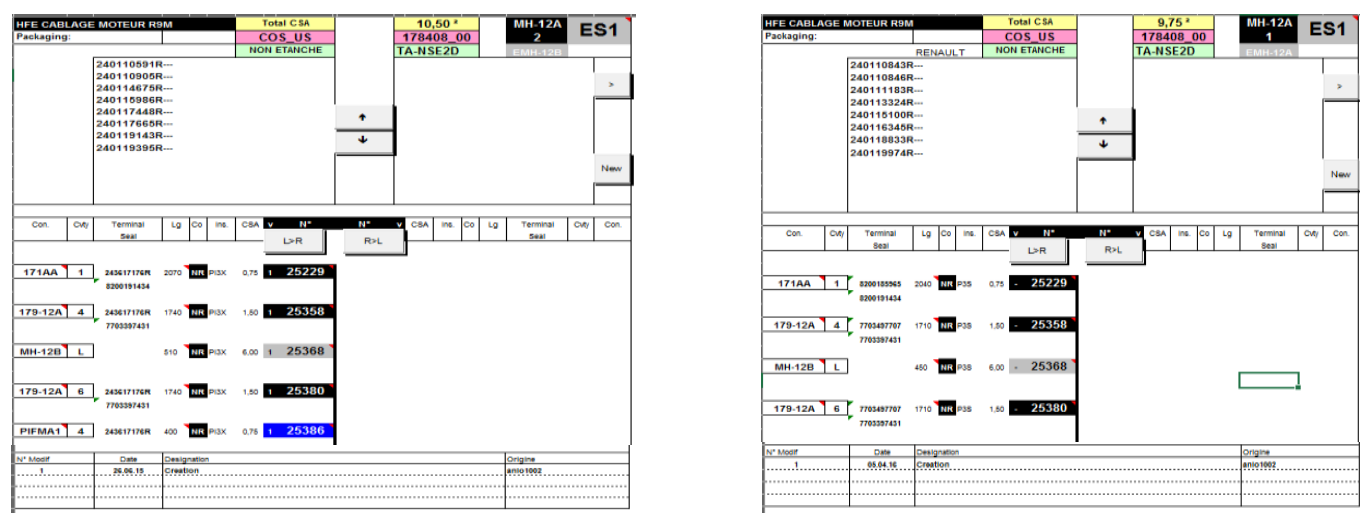

Figure 3. Welding sheet for welding $\mathrm{MH}-12 \mathrm{~A}$

a. before the change

b. after the change

Figure 4.a presents the current welding sheet for welding MH-12B, without removing the dead wires 25387,25388 and 25389. Initially, this weld had a total section of $18 \mathrm{~mm}$, and after removing the wires, this weld will have the section $12 \mathrm{~mm}$. Figure 4.b shows the welding sheet after modification for $\mathrm{MH}-12 \mathrm{~B}$ welding.

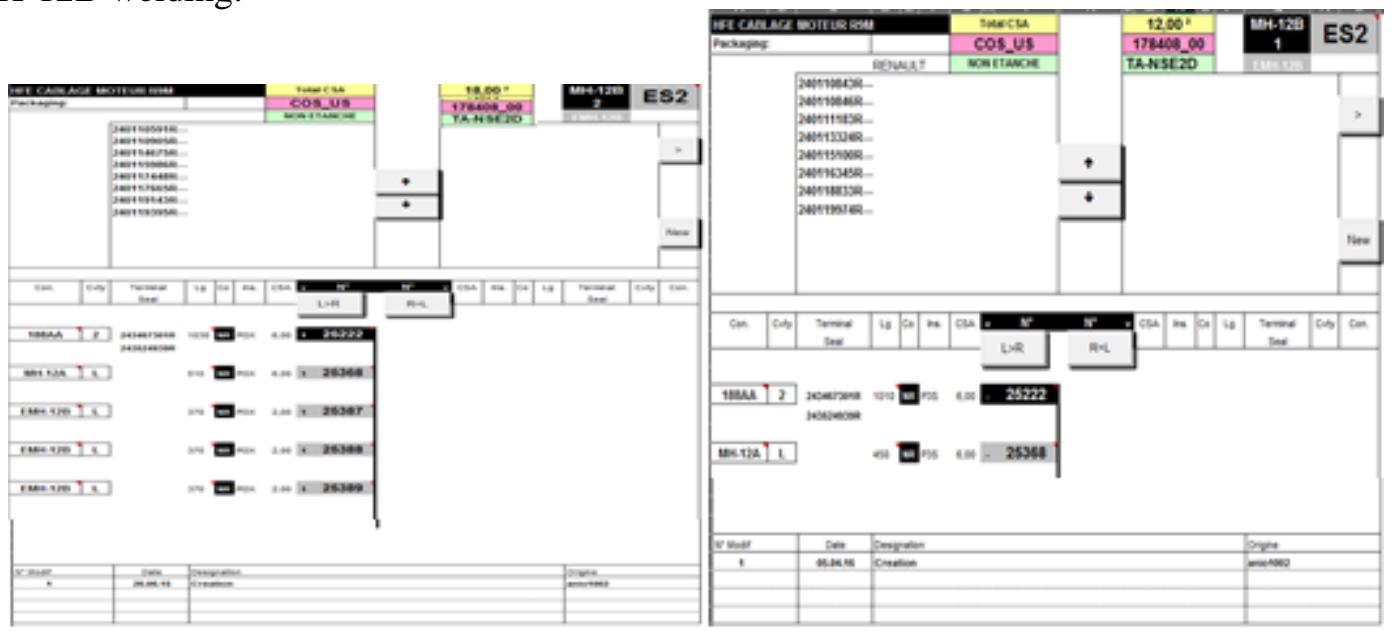

Figure 4. Welding sheet for welding MH-12B

a. before the change

b. after the change

\section{Validation of changes}

In order to validate the proposed changes, a feasibility meeting is initially carried out together with the quality, cutting and assembly departments.

For changes in the type of splice, for the validation of this modification a wiring with the modified hue was made. This wiring was analyzed together with the research, quality and assembly departments. Following the analysis of the modified wiring, the following conclusions were obtained:

- there is a risk of not following the step splice;

- there is a risk that the wires underneath the tube will be visible;

- tubes with lengths greater than $150 \mathrm{~mm}$ and smaller than $10 \mathrm{~mm}$ diameter cannot be discontinuously tinted, as there is a risk that these tubes will be tinted often.

Therefore, this first amendment proposal is not feasible.

Regarding the proposal regarding the relocation of a relay in the relay and fuse box, its validation consists in testing the relay and fuse box electrically and visually, with the help of an electrical control stand. This electric control stand is a POKA YOKE system and so this second proposal can be applied without risk. 
With regard to the third proposal, the one for the validation of welds, together with the cutting department, 11 samples from each weld will be made, and these samples will be tensile tested using a specific tensile testing device [4].

In order to pass the tensile test, the samples must withstand a minimum force of $230 \mathrm{~N}$. This value is imposed by the customer and depends on the total section of the weld.

For testing, each sample is taken between the two movable jaws of the tensile test device and the START button is pressed. The test takes 5 seconds, during which time the value is displayed on the screen.

After repeating the test 11 times, the data is centralized and processed.

The following values were obtained after testing: $294 \mathrm{~N}, 281 \mathrm{~N}, 289 \mathrm{~N}, 295 \mathrm{~N}, 292 \mathrm{~N}, 279 \mathrm{~N}, 288 \mathrm{~N}$, $291 \mathrm{~N}, 282 \mathrm{~N}, 297 \mathrm{~N}, 283 \mathrm{~N}$.

Next, the data is validated, through the following steps [5]:

- The ordering of the data in ascending sense is performed and the following row is obtained:279, 281, 282, 283, 288, 289, 291, 292, 294, 295, 297.

- The average $\bar{X}$ is calculated with the help of the formula (1):

$$
\bar{X}=\left(\sum_{i=1}^{n} X_{i}\right) / n
$$

Where: $\mathrm{n}=11$, number of string values:

$$
\bar{X}=\frac{279+281+282+283+288+289+291+292+294+295+297}{11}
$$

$$
\bar{X}=288,2727
$$

- It will calculate the median $\mathrm{M}_{\mathrm{e}}$ with the help of the formula (2):

$$
\begin{gathered}
M e=X(n+1) / 2 \\
M_{e}=(11+1) / 2=6
\end{gathered}
$$

Therefore, it is the sixth value in the string:

$$
\mathrm{Me}=289
$$

- The dispersion $\mathrm{s}^{2}$ will be calculated with the help of the formula (3):

$$
\begin{gathered}
s^{2}=\left[\sum_{i=1}^{n}\left(X_{i}-\bar{X}\right)^{2}\right] /(n-1) \\
\mathrm{S}^{2}=\frac{(279-288,27)^{\wedge} 2+(281-288,27)^{\wedge} 2+(282-288,27)^{\wedge} 2+(283-288,27)^{\wedge} 2+(288-288,27)^{\wedge} 2}{(11-1)} \\
\mathrm{S}^{2}=38,2181
\end{gathered}
$$

- The average squared deviation $\mathrm{s}$ is calculated with the help of the formula (4):

$$
\begin{gathered}
s=\sqrt{s^{2}} \\
s=\sqrt{38,2181} \\
s=6,1820
\end{gathered}
$$

- The amplitude of the string $\mathrm{R}$ will be calculated $\mathrm{R}$ with the help of the formula (5):

$$
\begin{gathered}
R=X_{\max }-X_{\min } \\
R=297-279
\end{gathered}
$$




$$
\mathrm{R}=18
$$

- The asymmetry of the string $\beta$ will be calculated with the help of the formula (6):

$$
\begin{aligned}
& {\left[\sum_{i=1}^{n}\left(x_{i}-\bar{x}\right)^{3}\right]^{2}\left[\sum_{i=1}^{n}\left(x_{i},-\bar{x}\right)^{2}\right]^{3}} \\
& \beta=\frac{\left((279-288,27)^{\wedge} 3+(281-288,27)^{\wedge} 3+(282-288,27)^{\wedge} 3+(283-288,27)^{\wedge} 3+(288-288,27)^{\wedge} 3\right.}{\left(s^{2}\right)^{\wedge} 3} \\
& \beta=0,0021435
\end{aligned}
$$

Next, the normality of the data distribution is verified using the Shapiro - Wilk (S - W) test [6]. The application of the test consists in the calculation of a statistical parameter $\mathrm{W}$. If $\mathrm{W} \geq \mathrm{Wt}$, the data normality assumption can be accepted.

For the calculation of parameter $\mathrm{W}$ the following steps are performed:

- The value of the index $b$ will be calculated with the help of the formula (7):

$$
b=\sum_{i=1}^{k} a_{n-i+1}\left[X_{n-i+1}-X_{i}\right]
$$

Where: $\mathrm{k}=(\mathrm{n}-1) / 2, \mathrm{n}=11 ; \mathrm{k}=(11-1) / 2=5 ; \mathrm{i}=1,2,3,4,5$; $\mathrm{a}_{\mathrm{n}-\mathrm{i}+1}$ has the following values - table 1 :

Table 1 Parameter values for a

\begin{tabular}{|l|l|l|l|l|l|l|}
\hline $\mathrm{i}$ & 1 & 2 & & 3 & 4 & 5 \\
\hline $\mathrm{a}$ & 0,56 & 0,332 & & 0,226 & 0,143 & 0,07 \\
\hline
\end{tabular}

The value of index $b$ can be further calculated by replacing in formula (7) with the obtained values: $\mathrm{b}=0,56 *(297-279)+0,332 *(295-281)+0,226 *(294-282)+0,143 *(292-283)+0,07 *(291-288)$

$$
\mathrm{b}=18,937
$$

- The value of the index $\mathrm{W}$ will be calculated with the help of the formula (8):

$$
W=\frac{b^{2}}{\sum_{i=1}^{n}\left(X_{i}-\bar{X}\right)^{2}}
$$

$$
\begin{gathered}
\mathrm{W}=\frac{18,937^{\wedge} 2}{(279-288,27)^{\wedge} 2+(281-288,27)^{\wedge} 2+(282-288,27)^{\wedge} 2+(283-288,27)^{\wedge} 2+(288-288,27)^{\wedge} 2} \\
\mathrm{~W}=0,9383
\end{gathered}
$$

The parameter $\mathrm{W}_{\mathrm{t}}$ is chosen as follows: for the confidence level $(1-\beta)=1-0,0021435=0,98$ and for the number of measurements $\mathrm{n}=11, \mathrm{~W}_{\mathrm{t}}=0,817$. As $\mathrm{W}=0,9383>\mathrm{W}_{\mathrm{t}}=0,817$, so it falls into $\mathrm{W} \geq \mathrm{W}_{\mathrm{t}}$, it follows that the obtained data have a normal distribution [7].

In continuation, the following calculation steps are performed:

- It goes to the elimination of aberrant data with the help of formulas (9) și (10):

$$
\begin{gathered}
u_{1}=\frac{\bar{X}-X_{1}}{s} \\
u_{n}=\frac{X_{n}-\bar{X}}{s} \\
\boldsymbol{u}_{\mathbf{1}}=\frac{\mathbf{2 8 8 , 2 7}-\mathbf{2 7 9}}{\mathbf{6 , 1 8 2}}=1,4999 \\
\boldsymbol{u}_{\mathbf{1 1}}=\frac{\mathbf{2 9 7}-\mathbf{2 8 8 , 2 7}}{\mathbf{6 , 1 8 2}}=1,4117
\end{gathered}
$$

For $\mathrm{n}=11$ and $\alpha=0,025$, index $\mathrm{h}=2,36$.

Because $\boldsymbol{u}_{1}<\mathrm{h}$, respectively $1,49<2,3$, and $\boldsymbol{u}_{11}<\mathrm{h}$, respectively $1,41<2,36$, it turns out that the data obtained are not aberrant.

- The population average indicator $\mathrm{M}$ is calculated using the formula (11): 


$$
\bar{X}-\frac{t_{1-\alpha / 2, v} \cdot s}{\sqrt{n}}<M<\bar{X}+\frac{t_{1-\alpha / 2, v} \cdot s}{\sqrt{n}}
$$

Where: $\mathrm{v}=\mathrm{n}-1, \mathrm{v}=11-1=10 ; 1-\alpha=0,95 ; \mathrm{t}=2,288$

$$
\begin{aligned}
& 288,27-\frac{2,288 * 6,182}{\sqrt{11}}<\mathrm{M}<288,27+\frac{2,288 * 6,182}{\sqrt{11}} \\
& 284,0079<\mathrm{M}<292,5374
\end{aligned}
$$

- The population dispersion $\sigma^{2}$ will be calculated with the help of formula (12):

$$
\frac{s^{2}(n-1)}{\chi^{2}{ }_{1-\alpha / 2, v}}<\sigma^{2}<\frac{s^{2}(n-1)}{\chi_{\alpha / 2, v}^{2}}
$$

Where:

$$
\begin{aligned}
& \chi^{2}{ }_{1-\alpha / 2, v}(0,025)=3,247 \\
& \chi_{\alpha / 2, v}{ }^{(0,975)}=20,483
\end{aligned}
$$

$$
\begin{gathered}
\frac{38,2181 *(11-1)}{20,483}<\sigma^{2}<\frac{38,2181 *(11-1)}{3,247} \\
18,65<\sigma^{2}<117,70
\end{gathered}
$$

- The range of natural tolerances of the population will be calculated using the formula (13) and (14), respectively the values for tensile forces. Thus, the lower limit and the upper limit will be calculated.

$$
\begin{gathered}
\mathrm{Li}=X-s \mathrm{~K}^{\prime} 2 \\
\mathrm{Ls}=X+s \mathrm{k}^{\prime} 2
\end{gathered}
$$

Where: $\boldsymbol{k}^{2}=3,26$

$$
\begin{aligned}
\mathrm{Li} & =268,119=288,27-20,15 \\
\mathrm{Ls} & =308,426=288,27+20,15
\end{aligned}
$$

Therefore, the minimum value of the force obtained from the calculations is $\mathrm{Li}=268,119 \mathrm{~N}$. This value is higher than the minimum value admitted by the customer, respectively $230 \mathrm{~N}$.

In conclusion, the modification of the welds is feasible and can be applied on the studied wiring.

\section{Conclusions}

In this paper, 3 possible modifications applied to an electrical wiring are presented and analyzed, in order to reduce the cost with the materials used to obtain it. The 3 changes are aimed at: changing the type of hue, moving a relay in the relay box and modifying some wires that have no electrical role. All these changes were subjected to analyzes of the risks of their implementation. The results of these analyzes were as follows:

- To validate the change in the type of splice, wiring harness splicing modified subject to analyzes carried out in collaboration with the departments of research, quality and assembly, showed that this first proposal for modification is not feasible.

- In order to validate the modification regarding the relocation of a relay in the relay and fuse box, by testing the relay and fuse box modified - electrically and visually, with the help of an electrical control stand -, it was demonstrated that this second proposal is feasible, therefore it can be applied without risk.

- Regarding the third proposal, the one for the validation of welds, all 11 samples from each weld were subjected to traction using the specific tensile testing device. The minimum value of the force obtained from the calculations was $268,119 \mathrm{~N}$, which is higher than the minimum value admitted by the client, respectively $230 \mathrm{~N}$. Thus, the modification of the welds is feasible and can be applied on the studied electrical wiring. 
In conclusion, of the 3 proposals for modifications applied to an electrical wiring, in order to reduce the cost with the materials used to obtain it, proposal 2 and proposal 3 have proved to be feasible and can be applied in practice.

\section{References}

[1] Bălteanu A., Băldea M., Adapting to the times of global economic crisis of an enterprise by increasing labor productivity at a work station due to automation of afferented operations, Review of Management and Economic Engineering, 5th International Management Conference "From Management of Crisis to Management in a Time of Crisis", Cluj-Napoca, Romania, 22nd and 24th of September 2016 ISI Web of Knowledge" Proceedings Database, 2016.

[2] Bălteanu A., Politici de producţie şi de personal in cadrul unei societăţi producătoare de cablaje electrice (2), Revista de Management şi Inginerie Economică, vol. 11 / nr. 2 (40), Cluj-Napoca, Editura Risoprint, ISSN: 1583 - 624 x, p.137-143, 2011.

[3] Bălteanu A., Politici de producţie şi de personal in cadrul unei societăţi producătoare de cablaje electrice (1), Revista de Management şi Inginerie Economică, vol. 10 / nr. 1 (39), Cluj-Napoca, Editura Risoprint, ISSN: $1583-624$ x, p.139-147, 2011.

[4] Desforges, X., Habbadi, A., Geneste, L, Distribute machining control and monitoring using smart sensors/actuators, Journal of Intelingent Manufacturing 15, pp 39-53, ISSN 0956-5515, 2004.

[5] Habaibeh A., Gindy N., A new approach for systematic design of condition monitoring systems for milling processes, Journal of Materials Processing Technology, Vol 107, pp. 243-251, ISSN: 0924-0136, 2010.

[6] Krishnakumar, K., Melkote, S.,N., Machining fixture layout optimization, International Journal of Machine Tools and Manufacture, 40, pp. 579-598, ISSN 0890-6955, 2000.

[7] Rivin E., Tooling Structure - Interface between cutting edge and machine tool, Annals of the CIRP 49/2, pp. 591-634, ISSN 0007-8506, 2008. 